\title{
[Title] The role of thrombophilia testing in women with adverse pregnancy
}

outcomes

\author{
[Running title] Thrombophilia testing in obstetrics
}

Julia Unterscheider MD PhD MRCOG MRCPI FRANZCOG DDU, ${ }^{1, *}$ Stefan C Kane MBBS BA BMedSC FRANZCOG DDU, ${ }^{2}$ Briony Cutts MD FRACP FRCPA, ${ }^{3}$ Helen Savoia FRCPA, ${ }^{3}$ Joanne M Said MBBS FRANZCOG CMFM PhD Grad Dip Epid ${ }^{4}$

${ }^{1}$ Consultant Obstetrician and Clinical Senior Lecturer, The University of Melbourne, Department of Maternal Fetal Medicine, Royal Women's Hospital, Melbourne, Parkville VIC 3052, Australia

${ }^{2}$ Consultant Obstetrician and Fellow in Maternal Fetal Medicine, The University of Melbourne, Department of Maternal Fetal Medicine, Royal Women's Hospital, Melbourne, Parkville VIC 3052 , Australia

${ }^{3}$ Consultant Haematologist, Department of Haematology, Royal Women's Hospital, Melbourne, Parkville VIC 3052, Australia

${ }^{4}$ Associate Professor, University of Melbourne, Subspecialist in Maternal Fetal Medicine and Head of the Department of Maternal Fetal Medicine, Sunshine Hospital, Melbourne, St Albans VIC 3021, Australia

*Correspondence: Julia Unterscheider. Email: julia.unterscheider@thewomens.org.au

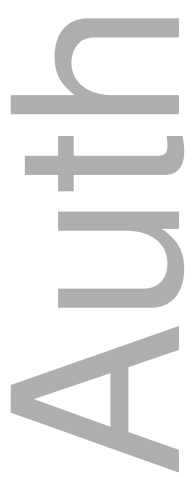

This is the author manuscript accepted for publication and has undergone full peer review but has not been through the copyediting, typesetting, pagination and proofreading process, which may lead to differences between this version and the Version of Record. Please cite this article as $\underline{\text { doi: } 10.1111 / \operatorname{tog} .12366}$

This article is protected by copyright. All rights reserved 
Received Date : 22-May-2016

Revised Date : 28-Jul-2016

Accepted Date : 04-Sep-2016

Article type : Reviews

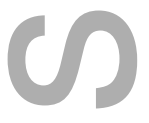

The role of thrombophilia testing in women with adverse pregnancy outcomes

\section{Key content}

- Thrombophilias, whether inherited or acquired, have been linked to adverse pregnancy outcomes, such as pre-eclampsia, placental abruption, fetal growth restriction, stillbirth, thrombosis and recurrent pregnancy loss in many but not all case-control studies.

- Prospective cohort studies have confirmed that the majority of women who carry inherited thrombophilias do not experience adverse pregnancy outcomes.

- Thrombophilia testing is expensive and the positive yield of such investigations, in particular with respect to informing management in a subsequent pregnancy, is low.

- This review critically evaluates the benefit of thrombophilia testing in the obstetric setting and provides guidance with respect to care of women in a subsequent pregnancy following an adverse outcome.

\section{Learning objectives}

- To understand the relationship between the various thrombophilias and pregnancy complications.

This article is protected by copyright. All rights reserved 
- To appreciate the appropriate role of screening for and treating thrombophilias in the context of such pregnancy complications.

\section{Ethical issues}

- Should thrombophilia testing following adverse pregnancy outcome be informed by specific factors in the clinical history?

- Can placental histopathology help guide selection of women requiring further assessment?

- Thrombophilias may be associated with thromboembolic complications in later life - is it therefore ethical to withhold testing in women with a history of adverse pregnancy outcomes?

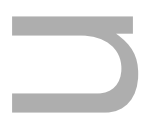

Keywords: inherited and acquired thrombophilia / obstetrical antiphospholipid syndrome / placenta-mediated pregnancy complications

\section{Introduction}

Placenta-mediated pregnancy complications, such as recurrent pregnancy loss, fetal growth restriction, stillbirth, severe pre-eclampsia and placental abruption, have been associated with a maternal genetic predisposition to thrombosis expressed by a positive thrombophilia assessment (Box 1). ${ }^{1-5}$ Prevention of such placenta-mediated complications, which collectively complicate up to $15 \%$ of pregnancies, is a major issue for perinatal health.

The hypercoagulable state of pregnancy increases the risk of thrombotic complications in vulnerable women, such as those with inherited thrombophilias, which occur with high prevalence in unselected populations. The association between thrombophilias and adverse pregnancy outcomes has been well described previously; however, more recent studies have failed to confirm these findings. Whether or not this association reflects direct causation remains uncertain. As a result, the clinical relevance of a positive inherited thrombophilia test result is likely to be limited, as there is no evidence that altering pregnancy management on the basis of this result improves outcomes.

Anticoagulant treatment options include low-dose aspirin, unfractionated heparin and lowmolecular-weight heparin (LMWH). Heparin increases the effect of the natural anticoagulant 
antithrombin, whereas aspirin inhibits platelet aggregation. Heparin is not a benign intervention and necessitates burdensome subcutaneous injections on a daily or twice-daily basis. It is also expensive, and has potential adverse effects, mostly minor, in approximately $40 \%$ of women, which include local skin reactions (pain, itching, swelling, bruising), an increased risk of bleeding, heparin-induced thrombocytopenia, and osteopenia or osteoporotic fractures, in addition to precluding epidural analgesia if not discontinued in time.

There is a plethora of published studies on this topic. Unfortunately, significant methodological heterogeneity exists among studies regarding dosing regimens, duration and type of treatment, blinding, reporting of secondary outcomes and study quality. Furthermore, lack of a 'no-treatment' (or placebo) arm in some studies impedes assessment of a risk-benefit ratio for individual interventions. ${ }^{6}$

The Obstetrician \& Gynaecologist has previously published a review on inherited thrombophilias, pregnancy and treatment. ${ }^{7}$ In their review, Myers and Pavord stated that laboratory testing should only be performed whenever the results influence decisions on therapy or prevention. This conclusion is echoed in a 2016 guideline, produced by the Anticoagulation Forum in the USA, ${ }^{8}$ which recommends that thrombophilia testing 'should only be performed when results will be used to improve or modify management'. Furthermore, the authors of this guideline state 'testing is performed farmore frequently than can be justified based on available evidence and that the majority of testing is not of benefit to the patient, but may actually be harmful'. In its 2016 Choosing Wisely initiative, ${ }^{9}$ the Society for Maternal and Fetal Medicine in the USA has urged clinicians to refrain from thrombophilia evaluation for women with histories of pregnancy loss, fetal growth restriction, severe pre-eclampsia and abruption. The problem with testing for underlying thrombophilias and modified management in a subsequent pregnancy can be illustrated with an example: evidence provided in a systematic review and meta-analysis ${ }^{2}$ reported an $81 \%$ increased risk of recurrent pregnancy loss in women with prothrombin gene mutation; while this significant relationship is acknowledged, there is currently no evidence that acting on these test results alters pregnancy course and outcome. The same argument applies to factor V Leiden mutation (FVL) status and the small increased risk of late pregnancy loss. ${ }^{5}$

The cost of a full thrombophilia screen is $\mathrm{f} 250.82$ (NHS Thrombophilia screening guidelines). ${ }^{10} \mathrm{It}$ might be questioned whether it is worth performing an expensive test if it does not change management. One might argue that testing offers an opportunity to identify women with thrombophilia, alerting these women and their healthcare providers to their lifetime risks of venous thrombosis with an opportunity for thromboprophylaxis during high-risk periods. That said, it may 
also increase the cost of obtaining life and other insurances, ${ }^{11}$ and given the heritable nature of most thrombophilias, it may have implications for family members as well.

The following review will summarise current knowledge regarding thrombophilia testing in women with adverse pregnancy outcomes through a review of evidence from recently published studies, trials and meta-analyses.

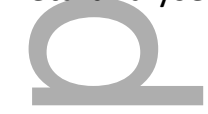

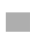

\section{Inherited thrombophilias}

Most studies concerning adverse pregnancy outcomes and their preventive strategies relate to women with inheritable coagulation disorders. An Australian case-control study of 230 women assessed the impact of inherited thrombophilia on pregnancy outcome and found an association between heterozygosity for the Factor $\mathrm{V}$ Leiden mutation and an increased risk of stillbirth and placental abruption. ${ }^{12}$ Overall, however, this study did not show a difference in prevalence of inherited thrombophilia among women with or without a history of adverse pregnancy outcomes. More recent, prospective studies have found no association between maternal thrombophilias and placenta-medicated pregnancy outcomes. ${ }^{13}$ An editorial comment in Obstetrics \& Gynecology ${ }^{14}$ eloquently highlighted the multifaceted complexity about thrombophilias and adverse pregnancy outcome: first, the relatively high prevalence of thrombophilic disorders in asymptomatic patients; second, the at-best weak association between thrombophilias and pregnancy outcomes; and third, the lack of beneficial treatment interventions.

The main trials evaluating the role of thromboprophylaxis in women with placenta-mediated pregnancy complications are summarised in Table 1. For the purpose of this review complications are subdivided into three groups: recurrent pregnancy loss, other severe placenta-mediated pregnancy complications, such as severe pre-eclampsia, fetal growth restriction, abruption and stillbirth, and placental histopathological lesions.

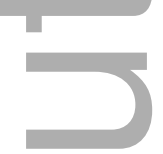

\section{[B head] Recurrent pregnancy loss}

While early pregnancy loss is very common, with at least $15 \%$ of clinically recognised pregnancies ending in miscarriage, recurrent pregnancy loss - defined as two or three more consecutive losses affects up to $5 \%$ or $1 \%$ of couples, respectively. ${ }^{15}$ There is continuing debate regarding the optimal definition of recurrent pregnancy loss. Although a 2015 consensus statement issued by the European Society of Human Reproduction and Embryology Special Interest Group ${ }^{16}$ highlighted the need for a 
consistent and generally accepted terminology in order to make meaningful comparisons between scientific studies in the field, no single best definition was presented. It did suggest, however, that losses which are not consecutive, intrauterine or visualised (e.g. 'biochemical' pregnancies) be included in the definition.

Numerous antecedents have been postulated as contributing causes to recurrent pregnancy loss including fetal structural or genetic anomalies, mechanical factors such as uterine anomalies or cervical insufficiency and maternal factors such as medical disorders and thrombophilias. This range of potential underlying causes results in significant heterogeneity of studied pregnancies. ${ }^{17,18}$

The role of LMWH in the prevention of pregnancy complications remains inconclusive, but is likely to be limited. No prospective studies have demonstrated benefit from treatment of women with recurrent pregnancy loss based on heritable thrombophilia status. ${ }^{19,20}$ The concept that LMWH could improve pregnancy outcomes in women with one fetal loss and a constitutional thrombophilic disorder (FVL, PT gene mutation, Protein S deficiency) was introduced by a small single-centre study in France, ${ }^{21}$ which found that treatment with enoxaparin increased mean birthweight (3043 g versus $2742 \mathrm{~g} ; P=0.0005)$ and live-birth rates overall ( $86 \%$ versus $29 ; P<0.001)$ when compared with treatment with low-dose aspirin alone. Given these encouraging results, the LIVE-ENOX study ${ }^{22}$ recruited 180 women with recurrent pregnancy loss (two or more consecutive pregnancies) to a multicentre, prospective, randomised, open-label trial, at 12 centres in Israel, and evaluated pregnancy outcomes comparing $40 \mathrm{mg}$ versus $80 \mathrm{mg}$ enoxaparin daily. Brenner el al. ${ }^{22}$ showed similar live-birth rates in both arms and concluded that LMWH represented an effective and safe option, with the majority of treated pregnancies resulting in a favourable outcome. The absence of a placebo arm, however, is a significant limitation of this study that precludes a clear assessment of enoxaparin's overall impact.

A single centre, open label randomised controlled trial comparing LMWH/low-dose aspirin (dalteparin $5000 \mathrm{IU}$ plus aspirin $81 \mathrm{mg}$ daily) and low-dose aspirin alone in 88 women with recurrent pregnancy loss and a thrombophilia or positive autoantibody screen (HepASA Trial) ${ }^{23}$ was unable to demonstrate a benefit of LMWH treatment with respect to live-birth rates. Similar to the findings of another study, ${ }^{24}$ the additional treatment with LMWH conferred an increased rate of pregnancy loss when compared with treatment with aspirin alone. The authors concluded that, regardless of treatment regimen, number of prior losses or positive antiphospholipid antibody status, almost $80 \%$ of women with recurrent pregnancy loss had a subsequent successful pregnancy outcome. ${ }^{23} \mathrm{~A}$ limitation of the HepASA Trial was its statistical power, given the trial was designed to have a sample size of 200 women, but was stopped early because of recruitment difficulty and funding following an 
interim analysis showing no significant difference between the treatment groups. The treatment with LMWH increased birthweight slightly $(+155 \mathrm{~g}, P=0.627)$ and decreased the incidence of small for gestational age (three versus six cases), however, neither of these findings reached statistical significance.

In 2010, two prospective, multicentre, randomised controlled trials, $\mathrm{ALIFE}^{25}$ and SPIN, ${ }^{26}$ reported that antithrombotic prophylaxis did not improve pregnancy outcome in women with recurrent pregnancy loss. Over a four-year recruitment period, SPIN ${ }^{26}$ investigated 294 women with two or more consecutive pregnancy losses before 24 weeks of gestation in 14 sites in the UK and New Zealand. Participants were randomised to either pharmacologic intervention (treatment with enoxaparin $40 \mathrm{mg}$ and aspirin $75 \mathrm{mg}$ daily plus intensive surveillance) or intensive surveillance alone. Women with known antiphospholipid syndrome or a personal history of venous thromboembolism were excluded from the study. Thrombophilia testing was performed but not revealed until study completion. The study could not demonstrate a quantifiable benefit of pharmacologic intervention with respect to the primary outcome (pregnancy loss rate), which was $22 \%$ in the treatment group and $29 \%$ in the control group (odds ratio $0.91 ; 95 \% \mathrm{Cl} 0.52-1.59$ ). While non-serious adverse events were more common in the treatment group, serious events, such as ante- or postpartum haemorrhage, were evenly distributed between the groups. A second randomised controlled trial ${ }^{25}$ investigated the role of aspirin plus heparin or aspirin alone in women with recurrent pregnancy loss. The three-arm Anticoagulants for Living Fetuses (ALIFE) trial ${ }^{25}$ enrolled 364 women with a history of unexplained recurrent pregnancy loss before 20 weeks of gestation who were attempting to conceive or were less than six weeks' pregnant. Women with obstetrical antiphospholipid syndrome were excluded from the study, and $15.6 \%$ of recruited women had a positive thrombophilia screen. Once pregnancy was confirmed sonographically, the first group started treatment with aspirin $80 \mathrm{mg}$ in addition to nadroparin 2850 IU subcutaneously daily, the second group received aspirin alone and the third group received placebo. While there was no statistically significant difference with respect to live-birth rates among the groups ( $54.5 \%$ combination therapy versus $50.8 \%$ aspirin alone versus $57.0 \%$ placebo), live-birth rates were highest in the placebo group. Among women who achieved a pregnancy, the live birth rates were $69.1 \%, 61.6 \%$ and $67.0 \%$, respectively. Similarly, the HABENOX multicentre randomised controlled trial, ${ }^{27}$ which evaluated the benefit of thromboprophylactic treatment in a cohort of 207 women (25\% carrying a thrombophilic mutation) with recurrent or late pregnancy loss, found no benefit with regard to improvements in live-birth rate, pregnancy complications, neonatal outcome or adverse effects. 
A Cochrane review ${ }^{6}$ determining whether anticoagulant treatment improves the chance of a livebirth in women with a history of at least two unexplained miscarriages with or without inherited thrombophilia concluded that neither low-dose aspirin alone nor LMWH/low-dose aspirin have a demonstrable benefit with respect to live-births: low-dose aspirin versus placebo (risk ratio $0.94, \mathrm{Cl}$ 95\% 0.80-1.11, $n=256$ ), LMWH versus low-dose aspirin (risk ratio 1.08, Cl 95\% 0.93-1.26, $n=239$ ), $\mathrm{LMWH}$ /low-dose aspirin versus no treatment (risk ratio 1.01, $\mathrm{Cl} 95 \% 0.87-1.16, n=322$ ). ${ }^{6}$ In addition, a 2016 meta-analysis ${ }^{20}$ of randomised controlled trials comparing LMWH with no LMWH in women with inherited thrombophilia and previous late or recurrent early pregnancy loss suggested no benefit from additional treatment with LMWH. The authors concluded their meta-analysis with recommendations not to test women for inherited thrombophilias in this setting, and to refrain from using LMWH to prevent recurrent pregnancy loss. ${ }^{20}$

The presumption that anticoagulant therapy has the potential to improve pregnancy outcome in women with otherwise unexplained recurrent pregnancy loss is based on the hypothesis that thrombotic events in the placental circulation could cause these adverse outcomes. ALIFE and SPIN both large, good quality randomised controlled trials - together with recent meta-analyses have presented convincing negative evidence against screening and treatment of these women. The continuing ALIFE2 study, $^{28}$ which commenced recruitment in January 2013 , will evaluate the efficacy of LMWH in 776 women with inherited thrombophilia and recurrent pregnancy loss (two or more recurrent pregnancy losses) and/or a history of intrauterine fetal death. The study has extended recruitment to additional sites because of slow enrolment.

Given this overwhelming lack of an effective intervention to treat recurrent pregnancy loss based on thrombophilia status, it appears there is no indication for routine testing for inherited thrombophilias in women with recurrent pregnancy loss. Nonetheless, the authors agree with Skeith et al. ${ }^{20}$ that an individual patient data meta-analysis could provide additional clarification on the impact of treatment in women with specific inherited thrombophilias (Box 2).

\section{[B head] Other severe placenta-mediated pregnancy complications}

Pregnancy complications classified as 'placenta-medicated' share a presumed common pathophysiology of inappropriate coagulation pathway activation and placental developmental dysfunction. ${ }^{29}$ While such conditions (severe pre-eclampsia, fetal growth restriction, placental abruption, stillbirth) may occur in isolation, a significant overlap is commonly evident. In addition, all 
conditions carry significant recurrence risks and a consequent imperative for effective preventive treatment in subsequent pregnancies.

In 1974, Buyse et al. ${ }^{30}$ published a case report on three women with repeated extensive placental infarction leading to intrauterine death or severe dysmaturity. Anticoagulation in subsequent pregnancies (from the beginning of the second trimester until confinement) resulted in remarkably good outcomes. This apparent benefit from heparin's anticoagulant properties is biologically plausible, given that adverse placenta-medicated pregnancy complications occur as a result of microand macrovascular thrombosis. Evidence-based treatment in women with a history of severe placental disease is often impeded by emotionally charged patient requests, and clinicians have consequently embraced widespread off-label use of heparin despite the lack of good-quality evidence of a favourable benefit/harm profile.

In 2011, Kupferminc et al. ${ }^{31}$ reported a significantly improved subsequent pregnancy outcome in women with inherited thrombophilias and a history of severe pregnancy complications (severe preeclampsia, fetal growth restriction less than fifth centile, placental abruption, stillbirth at more than 20 weeks of gestation) when treated with LMWH. Their retrospective case-control study evaluated 116 women: 87 women received enoxaparin $1 \mathrm{mg} / \mathrm{kg}$ and 29 women constituted the control group (these women received antenatal care elsewhere but delivered in the treatment hospital). Treatment with LMWH showed an impressive reduction in recurrent adverse outcome (55\% versus 7\%). The results of prospective trials in this population have been variable. In 2009, Rey et al. ${ }^{32}$ showed a beneficial effect on a composite outcome of recurrent placenta-mediated pregnancy complications in non-thrombophilic women receiving treatment with LMWH (dalteparin $4000 \mathrm{IU}$ daily versus no therapy). Although the trial was discontinued early because of slow recruitment, LMWH reduced the risk of recurrent adverse outcome three-fold (5.5\% treatment group versus $23.6 \%$ control group). The Italian HAPPY trial (Heparin in pregnant women with adverse pregnancy outcome to improve rate of successful pregnancy) ${ }^{33}$ recruited 128 women regardless of thrombophilia status with a history of severe pre-eclampsia, HELLP syndrome, intrauterine fetal death, fetal growth restriction and/or placental abruption and randomised them to either nadroparin 3800 IU subcutaneously or routine medical surveillance. Nadroparin did not reduce late pregnancy complications in women at risk of recurrence $(P=0.76)$.

The FRUIT trial ${ }^{34}$ recruited women prior to 12 weeks of gestation with heritable thrombophilia (without antiphospholipid antibodies) and previous early-onset hypertensive disease (severe preeclampsia, HELLP syndrome) and/or previous small for gestational age requiring delivery at less than 34 weeks. Between 2000 and 2009, 139 women were randomised to either treatment with 
dalteparin 5000 IU subcutaneously plus low-dose aspirin daily or aspirin alone, with a primary endpoint of recurrence of early-onset hypertensive disorders at less than 34 weeks. The study was carried out in the Netherlands, Sweden and Australia, and each country used different doses of aspirin (80 mg, $75 \mathrm{mg}$ and $100 \mathrm{mg}$, respectively). The addition of LMWH to aspirin was shown to reduce the recurrence of hypertensive disorders at less than 34 weeks of gestation with a risk difference of $8.7 \%$, although there was no benefit observed across all gestational ages. While not statistically significant, more women in the aspirin-alone group developed severe pre-eclampsia $(21.7 \%$ versus $15.7 \%)$ when compared with the combined treatment group. In addition, there were four venous thromboembolism events (5.7\%) in the aspirin group and none in the LMWH and aspirin group.

Between 2000 and 2012, the TIPPS trial ${ }^{35}$ recruited 289 women with confirmed thrombophilias or previous placenta-mediated pregnancy complications and randomly allocated them to either antepartum dalteparin (5000 IU subcutaneously once daily until 20 weeks, and twice daily thereafter) or no treatment. In contrast to other studies, TIPPS did not exclude women with antiphospholipid antibodies, which occurred in $7.6 \%$ of studied women. The trial did not show a beneficial effect of antenatal anticoagulation with dalteparin with respect to its primary composite outcome (early onset severe pre-eclampsia, fetal growth restriction, pregnancy loss, venous thromboembolism). Minor bleeding complications were more common in the dalteparin group than in the no-treatment group (19.6\% versus 9.2\%; $P=0.01$ ). A comment titled 'TIPPing practice away from anticoagulation in pregnancy ${ }^{\prime 36}$ praised the trial investigators for their methodologically rigorous study design using pragmatic eligibility criteria, which make their convincingly negative results broadly generalisable to pregnant women with thrombophilias.

Most recently, results of the French HEPEPE trial (Prevention of maternal and perinatal complications by enoxaparin in women with previous severe pre-eclampsia) ${ }^{37}$ were presented at the Society for Maternal and Fetal Medicine's 36th Annual Scientific Meeting in Atlanta. This open-label prospective randomised controlled trial (NCT00986765) examined the role of enoxaparin in the prevention of placenta-mediated pregnancy complications. Over a six-year period, 257 women were randomised to either treatment with enoxaparin $4000 \mathrm{IU}$ subcutaneously daily in combination with aspirin $100 \mathrm{mg}$ daily versus aspirin alone. The trial showed no difference in primary composite outcomes (severe pre-eclampsia, fetal growth restriction, abruption, perinatal death) between the groups. $^{37}$

There is international agreement that treatment with low-dose aspirin reduces the recurrence of placenta-medicated pregnancy complications, in particular severe pre-eclampsia (17\% risk 
reduction) and fetal growth restriction (10\% risk reduction). ${ }^{38}$ There is currently insufficient evidence to support the use of LMWH in patients at risk of recurrent placenta-medicated pregnancy complications. While smaller unregistered, retrospective or single-centre studies may have suggested a beneficial effect of LMWH, these study findings have now been superseded by highquality evidence from rigorous randomised controlled trials. ${ }^{33-35}$

More recently, there has been a movement towards selective thrombophilia screening, if at all, in the evaluation of stillbirth. ${ }^{39}$ Despite the lack of a clear association between stillbirth and maternal thrombophilia, most women are routinely screened, and most international guidelines recommend some form of screening, ${ }^{40-42}$ particularly if stillbirth occurred in the context of fetal growth restriction, pre-eclampsia, maternal thrombosis and/or a maternal family history of thrombosis. In 2016 Silver et al. ${ }^{39}$ showed that, in fact, most maternal and fetal thrombophilias were not associated with stillbirth. In their secondary analysis of data from the Stillbirth Collaborative Research Network, maternal factor $V$ Leiden was only weakly associated with stillbirth. The authors concluded that routine testing for heritable thrombophilias as part of an evaluation for possible causes of stillbirth should not be performed. In the light of this evolving evidence, it would be timely for colleges and bodies endorsing routine thrombophilia screening to review their recommendations for stillbirth assessment.

\section{[B head] Placental histopathological lesions}

Although the placentas of thrombophilic women may be completely unremarkable on examination, placental abnormalities such as decidual vasculopathy, thrombosis in vessels in the decidua basalis, placental infarcts, increased syncytial knotting, maternal floor infarction, fetal thrombotic vasculopathy, vasculitis and chronic villitis have been linked to adverse pregnancy outcomes in women with thrombophilic mutations. ${ }^{43,44}$ While placental examination may relay crucial information to benefit the immediate care of mother and infant, predict possible recurrence risks, guide care in a subsequent pregnancy and help explain adverse pregnancy outcome, the clinical significance of several histopathological lesions and as to whether these lesions are causative, contributory or entirely incidental is subject of much research and debate. ${ }^{45,46}$

Many et al. ${ }^{47}$ compared the placental pathology between 68 women with and without thrombophilia who had either severe pre-eclampsia, fetal growth restriction, placental abruption or stillbirth. Thrombophilic women delivered at an earlier gestational age (29.8 versus 33.8 weeks) resulting in lower birthweights than women without thrombophilia. The study found a higher incidence of 
hypoplastic placentae (without difference in the fetoplacental ratio), villous infarcts $(P<0.01)$, multiple infarcts $(P<0.05)$ and fibrinoid necrosis of decidual vessels $(P<0.05)$, suggesting an independent contribution of thrombophilias to adverse pregnancy outcomes. Similarly, Gogia and Machin ${ }^{48}$ established an association between specific placental lesions and maternal thrombophilias; maternal floor infarction (40 cases), massive perivillous fibrin deposition (87 cases), fetal thrombotic vasculopathy ( 7 cases), and fetal thrombotic vasculopathy and massive perivillous fibrin deposition (4 cases) were found to be associated with maternal thrombophilias in $16(40 \%), 20$ (23\%), 5 (71\%) and $2(50 \%)$ of these lesions, respectively.

In a 2011 review, Kingdom and Drewlo ${ }^{49}$ summarised the putative beneficial effects of heparin, not only as a placental anticoagulant, but also as having the potential to induce cytotrophoblast proliferation and reverse the natural anti-angiogenic tendency of first-trimester placental villi with anti-inflammatory properties via suppression of complement pathway activation. ${ }^{49,50}$ Kingdom and Drewlo concluded that, irrespective of thrombophilia status, treatment with LMWH may be indicated in pregnancies at risk of early-onset severe pre-eclampsia.

Given the overlap between placental lesions and adverse perinatal outcomes, however, it is uncertain which placental features are strictly associated with a maternal and/or fetal thrombophilic state. It is debatable whether placental histopathological findings should inform maternal or paternal thrombophilia testing as, yet again, there is no proven established intervention (Box 3$)^{51}$

\section{Acquired thrombophilias/obstetrical antiphospholipid syndrome}

Antiphospholipid syndrome is defined by clinical manifestations that include thrombosis and/or fetal loss or pregnancy morbidity in patients with positive antiphospholipid serology, namely lupus anticoagulant, anticardiolipin antibodies and/or ß2-glycoprotein antibodies, on at least two occasions 12 weeks apart. ${ }^{52}$

It is imperative to note that antiphospholipid antibodies may be present in healthy patients without disease. This was elegantly demonstrated in a prospective blinded study in Ireland evaluating 810 asymptomatic low-risk primigravid women. Cooley et al. ${ }^{53}$ found that the incidence of positive acquired thrombophilia was $27.4 \%(n=222)$. Although women with antiphospholipid antibodies had higher rates of low birthweight and placental infarctions, there was no difference in rates of fetal loss or maternal disease overall when compared with the control group. Both groups delivered their babies at term (39.6 versus 39.4 weeks). This finding was echoed by a case-control study which revealed that pregnancy outcomes of women with antiphospholipid antibodies who do not meet the 
diagnostic criteria for antiphospholipid syndrome are generally favourable, and broadly comparable to the general obstetric population. ${ }^{54}$ In addition, it seems plausible that the primary cause of adverse pregnancy outcome in antiphospholipid syndrome relates to inflammation, rather than thrombosis. ${ }^{55}$

Based on somewhat limited data, ${ }^{56}$ aspirin and LMWH are recommended for obstetrical antiphospholipid syndrome, although there is no clear evidence that additional treatment with LMWH improves live-birth rates. ${ }^{24}$ Between 1997 and 2000, Farquharson et al. ${ }^{24}$ randomised 98 women with antiphospholipid syndrome to either treatment with low-dose aspirin (75 mg daily) or low-dose aspirin with LMWH (5000 IU daily subcutaneously). Live-birth rates in respective groups were $72 \%$ and $78 \%$ (odds ratio $1.39,95 \% \mathrm{Cl} 0.55-3.47$ ). Farquharson et al. concluded that the firstline treatment for women with obstetrical antiphospholipid syndrome should be low-dose aspirin. Although the use of LMWH in women with obstetrical antiphospholipid syndrome has been widely adopted, significant methodological heterogeneity between studies exists with regard to study population, intervention dose and timing, inclusion criteria and composite outcomes, leading to lack of conclusive evidence to support or withhold treatment.

Catastrophic antiphospholipid syndrome is a life-threatening disease conferring $50 \%$ mortality. It complicates less than $1 \%$ of antiphospholipid syndrome cases and is characterised by the onset of rapidly progressive and widespread thrombotic microangiopathy and by multi-organ failure. ${ }^{52}$ The severity of the maternal impact of this condition justifies aggressive therapy, and although studies are by definition small, treatment options shown to be effective have included anticoagulation, highdose steroids and plasma exchange. A recently managed case of catastrophic antiphospholipid syndrome encountered in the authors' institution is outlined in Box 4.

\section{Subsequent pregnancy care}

Prenatal care in women with previous adverse pregnancy outcomes should be provided in an empathetic, high-quality clinical care setting including emotional and mental health support, increased ultrasound surveillance, frequent visits and timely delivery. From a pharmacological intervention standpoint, treatment with LMWH in women with inheritable thrombophilias is currently not recommended. Efforts should be made to optimise treatment with aspirin, taking into account recent evidence to suggest that treatment with higher doses of aspirin (100-150 mg) administered ideally at nighttime, ${ }^{59}$ and commenced before 16 weeks of gestation ${ }^{60}$ improves subsequent pregnancy outcome. Although these data are derived from studies evaluating the 
recurrence reduction in the setting of pre-eclampsia and fetal growth restriction, dosing regimens may be adopted for the purpose of risk reduction in other placenta-mediated pregnancy complications as outlined above. Additional thromboprophylaxis with LMWH may be indicated in women with positive antiphospholipid syndrome antibodies, a history of catastrophic antiphospholipid syndrome or venous thromboembolism; ideally these women should be cared for in a multidisciplinary care setting with haematology input.

\section{Conclusion}

Thrombophilias are a diverse group of coagulation disorders associated with a predisposition to thrombotic events and placenta-mediated pregnancy complications. Evidence-based evaluation and treatment of patients with adverse pregnancy outcomes is often impeded by two factors: understandably emotionally charged parents who would 'do anything' to have a successful pregnancy outcome, and are thus accepting of unproven and unnecessary invasive treatments, and clinicians' uncertainty and the willingness to 'try anything' in this context. At present, within a heterogeneous set of underlying causes, inherited thrombophilias appear to be, at best, a weak contributor to adverse pregnancy outcomes. As always, association does not prove causation, and even if causation is established, effective therapies need to be available before routine testing can be justified. This is not the case for heritable thrombophilias, and as a result, testing for them in women who have sustained adverse pregnancy outcomes cannot currently be recommended. Their increased prevalence in this population does not justify testing with a view to improving long-term maternal health outcomes either, as this approach has not been shown to confer a net benefit, and has potential harms associated with insurance risk profiles and familial consequences of this genetic information.

In recent years, numerous studies, trials and meta-analyses have been published. Most recently, the well-conducted TIPPS trial clearly demonstrated negative evidence for heparin treatment in improving pregnancy outcomes among women with thrombophilias. It is important to present this information to patients in an empathetic manner and remind them, and ourselves, of the importance of primum non nocere- first doing no harm.

\section{Disclosure of interests}

There are no conflicts of interest. 


\section{Contribution to authorship}

JU instigated the article. JU, SCK and JMS performed the literature review. JU drafted the article and $\mathrm{SCK}, \mathrm{BC}, \mathrm{HS}$ and JMS revised it critically for important intellectual content. All authors approved the final version.

\section{References}

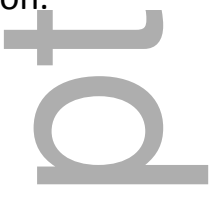

1. ReyE, Kahn SR, David M, Shrier I. Thrombophilic disorders and fetal loss: a meta-analysis. Lancet 2003;361:901-8.

2. Gao H, Tao FB. Prothrombin G20210A mutation is associated with recurrent pregnancy loss: a systematic review and meta-analysis update. Thromb Res 2015;135(2):339-46.

3. Kupferminc MJ, Eldor A, Steinman N, Many A, Bar-Am A, Jaffa A, et al. Increased frequency of genetic thrombophilia in women with complications of pregnancy. N Eng/ J Med 1999;340(1):9-13.

4. Robertson L, Wu O, Langhorne P, Twaddle S, Clark P, Lowe GD, et al; Thrombosis: Risk and Economic Assessment of Thrombophilia Screening (TREATS) Study. Thrombophilia in pregnancy: a systematic review. Br J Haematol 2006;132(2):171-96.

5. Rodger MA, Betancourt MT, Clark P, Lindqvist PG, Dizon-Townson D, Said J, et al. The association of factor $\mathrm{V}$ Leiden and prothrombin gene mutation and placenta-mediated pregnancy complications: a systematic review and meta-analysis of prospective cohort studies. PLoS Med 2010;7(6):e1000292.

6. de Jong PG, Kaandorp S, Di Nisio M, Goddijn M, Middeldorp S. Aspirin and/or heparin for women with unexplained recurrent miscarriage with or without inherited thrombophilia. Cochrane Database Syst Rev 2014;(7):CD004734.

7. Myers B, Pavord S. Heritable thrombophilias: implications for pregnancy and current evidence for treatment. The Obstetrician \& Gynaecologist 2011;13:225-30.

8. Stevens SM, Woller SC, Bauer KA, Kasthuri R, Cushman M, Streiff M, et al. Guidance for the evaluation and treatment of hereditary and acquired thrombophilia. J Thromb Thrombolysis 2016;41(1):154-64.

9. Branch DW, Silver RM. Practical work-up and management of recurrent pregnancy loss for the front-line clinician. Clin Obstet Gynecol 2016;59:535-8. 
10. Salisbury NHS Foundation Trust. Thrombophilia Screening Guidelines.

[http://www.icid.salisbury.nhs.uk/ClinicalManagement/Haematology/Pages/Thrombophillia ScreeningCG.aspx]

11. Joly Y, Ngueng Feze I, Simard J. Genetic discrimination and life insurance: a systematic review of the evidence. BMC Med 2013;11:25.

12. Said JM, Higgins JR, Moses EK, Walker SP, Monagle PT, Brennecke SP. Inherited thrombophilias and adverse pregnancy outcomes: a case-control study in an Australian population. Acta Obstet Gynecol Scand 2012;91(2):250-5.

13. Rodger MA, Carrier M, Le Gal G, Martinelli I, Perna A, Rey E, et al; Low-Molecular-Weight Heparin for Placenta-Mediated Pregnancy Complications Study Group. Meta-analysis of lowmolecular-weight heparin to prevent recurrent placenta-mediated pregnancy complications. Blood 2014;123:822-8.

14. Branch DW. The truth about inherited thrombophilias and pregnancy. Obstet Gynecol 2010;115(1):2-4.

15. Stephenson M, Kutteh W. Evaluation and management of recurrent early pregnancy loss. Clin Obstet Gynecol 2007;50: 132-45.

16. Kolte AM, Bernardi LA, Christiansen OB, Quenby S, Farquharson RG, Goddijn M, et al; ESHRE Special Interest Group, Early Pregnancy. Terminology for pregnancy loss prior to viability: a consensus statement from the ESHRE early pregnancy special interest group. Hum Reprod 2015;30:495-8.

17. van den Berg MM, van Maarle MC, van Wely M, Goddijn M. Genetics of early miscarriage. Biochim Biophys Acta 2012;1822:1951-9.

18. Kutteh WH. Novel strategies for the management of recurrent pregnancy loss. Semin Reprod Med 2015;33:161-8.

19. Bradley L, Palomaki GE, Bienstock J, Varga E, Scott JA. Can Factor V Leiden and prothrombin G20210A testing in women with recurrent pregnancy loss result in improved pregnancy outcomes? Results from a targeted evidence-based review. Genet Med 2012:14(1):39-50.

20. Skeith L, Carrier M, Kaaja R, Martinelli I, Petroff D, Schleußner E, et al. A meta-analysis of low-molecular-weight heparin to prevent pregnancy loss in women with inherited thrombophilia. Blood 2016;127:1650-5.

21. Gris JC, Mercier E, Quere I, Lavigne-Lissalde G, Cochery-Nouvellon E, Hoffet M, et al. Lowmolecular-weight heparin versus low-dose aspirin in women with one fetal loss and a constitutional thrombophilic disorder. Blood 2004;103:3695-9. 
22. Brenner B, Hoffman R, Carp H, Dulitsky M, Younis J for the LIVE-ENOX Investigators. Efficacy and safety of two doses of enoxaparin in women with thrombophilia and recurrent pregnancy loss: the LIVE-ENOX study. J Thromb Haemost 2005;3:227-9.

23. Laskin CA, Spitzer KA, Clark CA, Crowther MR, Ginsberg JS, Hawker GA, et al. Low molecular weight heparin and aspirin for recurrent pregnancy loss: results from the randomized, controlled HepASA Trial. J Rheumatol 2009;36:279-87.

24. Farquharson RG, Quenby S, Greaves M. Antiphospholipid syndrome in pregnancy: a randomized, controlled trial of treatment. Obstet Gynecol 2002;100:408-13.

25. Kaandorp SP, Goddijn M, van der Post JA, Hutten BA, Verhoeve HR, Hamulyak K, et al. Aspirin plus heparin or aspirin alone in women with recurrent miscarriage. $N$ Engl J Med 2010;362:1586-96.

26. Clark P, Walker ID, Langhorne P, Crichton L, Thomson A, Greaves M, et al. SPIN (Scottish Pregnancy Intervention) study: a multicenter, randomized controlled trial of low-molecularweight heparin and low-dose aspirin in women with recurrent miscarriage. Blood 2010;115:4162-7.

27. Visser J, Ulander VM, Helmerhorst FM, Lampinen K, Morin-Papunen L, Bloemenkamp KW, et al. Thromboprophylaxis for recurrent miscarriage in women with or without thrombophilia. HABENOX: a randomised multicentre trial. Thromb Haemost 2011;105:295-301.

28. de Jong PG, Quenby S, Bloemenkamp KW, Braams-Lisman BA, de Bruin JP, Coomarasamy A, et al. ALIFE2 study: low-molecular-weight heparin for women with recurrent miscarriage and inherited thrombophilia--study protocol for a randomized controlled trial. Trials 2015;16:208. doi: 10.1186/s13063-015-0719-9.

29. Greer IA, Aharon A, Brenner B, Gris JC. Coagulation and placenta-mediated complications. Rambam Maimonides Med J 2014;5(4):e0034.

30. Buyse FG,Wormgoor BH, Bernard JT, Koudstaal J. Anticoagulant therapy of patients with repeated placental infarction. Obstet Gynecol 1974;43:844-8.

31. Kupferminc MJ, Rimon E, Many A, Sharon M, Lessing JB, Gamzu R. Low molecular weight heparin treatment during subsequent pregnancies of women with inherited thrombophilia and previous severe pregnancy complications. J Matern Fetal Neonatal Med 2011;24:10425.

32. Rey E, Garneau P, David M, Gauthier R, Leduc L, Michon N, et al. Dalteparin for the prevention of recurrence of placental-mediated complications of pregnancy in women without thrombophilia: a pilot randomized controlled trial. J Thromb Haemost 2009;7(1):5864. 
33. Martinelli I, Ruggenenti P, Cetin I, Pardi G, Perna A, Vergani P, et al; HAPPY Study Group. Heparin in pregnant women with previous placenta-mediated pregnancy complications: a prospective, randomized, multicenter, controlled clinical trial. Blood 2012;119:3269-75.

34. de Vries JI, van Pampus MG, Hague WM, Bezemer PD, Joosten JH; FRUIT Investigators. Lowmolecular-weight heparin added to aspirin in the prevention of recurrent early-onset preeclampsia in women with inheritable thrombophilia: the FRUIT-RCT. J Thromb Haemost 2012;10(1):64-72.

35. Rodger MA, Hague WM, Kingdom J, Kahn SR, Karovitch A, Sermer M, et al; TIPPS Investigators. Antepartum dalteparin versus no antepartum dalteparin for the prevention of pregnancy complications in pregnant women with thrombophilia (TIPPS): a multinational open-label randomised trial. Lancet 2014;384:1673-83.

36. Gibson PS, Nerenberg KA. TIPPing practice away from anticoagulation in pregnancy. Lancet 2014;384:1648-9.

37. Haddad B, Winer N, Chitrit Y, Houfflin-Debarge V, Chauleur C, Bages K, et al. Prevention of maternal and perinatal complications by enoxaparin in women with previous severe preeclampsia (HEPEPE): an open-label, multicenter, prospective, randomized, controlled trial. Am J Obstet Gynecol 2016;214(1 Suppl):S452.

38. Duley L, Henderson-Smart DJ, Meher S, King JF. Antiplatelet agents for preventing preeclampsia and its complications. Cochrane Database Syst Rev 2007;(2):CD004659.

39. Silver RM, Saade GR, Thorsten V, Parker CB, Reddy UM, Botsch CD, et al. Factor V Leiden, prothrombin G20210A, and methylene tetrahydrofolate reductase mutations and stillbirth: the Stillbirth Collaborative Research Network. Am J Obstet Gynecol 2016 Apr 27. doi: 10.1016/j.ajog.2016.04.026. [Epub ahead of print]

40. Flenady V, King J, Charles A, Gardener G, Ellwood D, Day K, et al for the Perinatal Society of Australia and New Zealand (PSANZ) Perinatal Mortality Group. Clinical Practice Guideline for Perinatal Mortality. 2nd ed. Version 2.2, April 2009 [http://www.stillbirthalliance.org.au/doc/Section_1_Version_2.2_April_2009.pdf].

41. Leduc L, Farine D, Armson BA, Brunner M, Crane J, Delisle MF, et al. Stillbirth and bereavement: guidelines for stillbirth investigation. J Obstet Gynaecol Can 2006;28:540-52.

42. Royal College of Obstetricians and Gynaecologists. Late Intrauterine Fetal Death and Stillbirth. Greentop Guideline No. 55. London: RCOG; 2010 [https://www.rcog.org.uk/en/guidelines-research-services/guidelines/gtg55].

43. Redline RW. Placental pathology: a systematic approach with clinical correlations. Placenta 2008;29 Suppl A:S86-91.

This article is protected by copyright. All rights reserved 
44. Raspollini MR, Oliva E, Roberts DJ. Placental histopathologic features in patients with thrombophilic mutations. J Matern Fetal Neonatal Med 2007;20(2):113-23.

45. Benirschke K. The placenta in the litigation process. Am J Obstet Gynecol 1990;162:1445-50.

46. Benirschke K. Remarkable placenta. Clin Anat 1998;11:194-205.

47. Many A, Schreiber L, Rosner S, Lessing JB, Eldor A, Kupferminc MJ. Pathologic features of the placenta in women with severe pregnancy complications and thrombophilia. Obstet Gynecol 2001;98:1041-4.

48. Gogia N, Machin GA. Maternal thrombophilias are associated with specific placental lesions. Pediatr Dev Pathol 2008;11:424-9.

49. Kingdom JC, Drewlo S. Is heparin a placental anticoagulant in high-risk pregnancies? Blood 2011;118:4780-8.

50. Sobel ML, Kingdom J, Drewlo S. angiogenic response of placental villi to heparin. Obst Gynecol 2011;117:1375-83.

51. D'Souza R, Keating S, Walker M, Drewlo S, Kingdom J. Unfractionated heparin and placental pathology in high-risk pregnancies: secondary analysis of a pilot randomized controlled trial. Placenta 2014;35:816-23.

52. Cohen D, Berger SP, Steup-Beekman GM, Bloemenkamp KW, Bajema IM. Diagnosis and management of the antiphospholipid syndrome. BMJ 2010;340:c2541.

53. Cooley SM, Donnelly JC, Walsh T, Collins C, McMahon C, Gillan J, et al. The impact of positive acquired thrombophilia serology on ultrasound, obstetric outcome and the placenta in a low-risk primigravid population. Obstet Med 2011;4:15-19.

54. Soh MC, Pasupathy D, Gray G, Nelson-Piercy C. Persistent antiphospholipid antibodies do not contribute to adverse pregnancy outcomes. Rheumatology 2013;52:1642-7.

55. Salmon JE, Girardi G. Antiphospholipid antibodies and pregnancy loss: a disorder of inflammation. J Reprod Immunol 2008;77:51-6.

56. Kutteh WH. Antiphospholipid antibody-associated recurrent pregnancy loss: treatment with heparin and low-dose aspirin is superior to low-dose aspirin alone. Am J Obstet Gynecol 1996;174:1584-9.

57. Caron N, Rivard GE, Michon N, Morin F, Pilon D, Moutquin J, et al. Low-dose ASA response using the PFA-100 in women with high-risk pregnancy. J Obstet Gynaecol Can 2009;31:10227.

58. Rey E, Rivard GE. Is testing for aspirin response worthwhile in high-risk pregnancy? Eur J Obstet Gynecol Reprod Biol 2011;157:38-42. 
59. Ayala DE, Ucieda R, Hermida RC. Chronotherapy with low-dose aspirin for prevention of complications in pregnancy. Chronobiol Int 2013;30:260-79.

60. Bujold E, Roberge S, Nicolaides KH. Low-dose aspirin for prevention of adverse outcomes related to abnormal placentation. Prenat Diagn 2014;34:642-8.

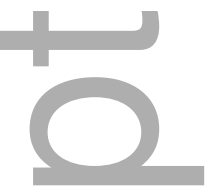

-

Box 1. Inherited and acquired thrombophilias

\section{Inherited thrombophilias:}

- Activated protein C (APC) resistance/factor V Leiden mutation

- Prothrombin G20210A mutation

- Antithrombin deficiency

- Protein C deficiency

- Protein S deficiency

- Factor XIII mutation

\section{Acquired thrombophilias:}

- Lupus anticoagulant

- B2-glycoprotein antibodies

- Anticardiolipin antibodies

\section{Box 2. A vignette}

A 33-year-old Gravida 3 Para 0 with a history of recurrent first trimester pregnancy loss undergoes thrombophilia screening and is found to be Factor V Leiden heterozygous. She is now 12 weeks pregnant. How would the knowledge of this finding alter antenatal care in this pregnancy?

\section{Box 3. A vignette}

A 23-year-old Para 1 delivered her first baby at 32 weeks. The pregnancy was complicated by severe fetal growth restriction and placental histopathology showed extensive fibrin deposition. Would you 
perform thrombophilia testing for her? How would the knowledge of an underlying thrombophilia impact on subsequent pregnancy care?

Box 4. A case of catastrophic antiphospholipid syndrome

A 25-year-old Para 0 books in for antenatal care at 15 weeks of gestation. Her first pregnancy four years previously was complicated by a fetal death in utero at 18 weeks of gestation as a consequence of catastrophic antiphospholipid syndrome with strongly positive ß2-glycoprotein and anticardiolipin antibodies. She developed significant microangiopathic haemolysis which responded to plasma exchange and steroid treatment. Placental histology revealed accelerated villous maturation, infarction and maternal vasculopathy. She attended pre-pregnancy counselling with a plan for antenatal thromboprophylaxis with aspirin $150 \mathrm{mg}$ nocte and LMWH (enoxaparin $60 \mathrm{mg}$ subcutaneously daily). Apart from mild thrombocytopenia she had an uneventful antenatal course, receiving high-risk care in a multidisciplinary setting. Following induction of labour at 38 weeks of gestation, she delivered a healthy baby boy weighing $3480 \mathrm{~g}$. She received postpartum thromboprophylaxis for six weeks.

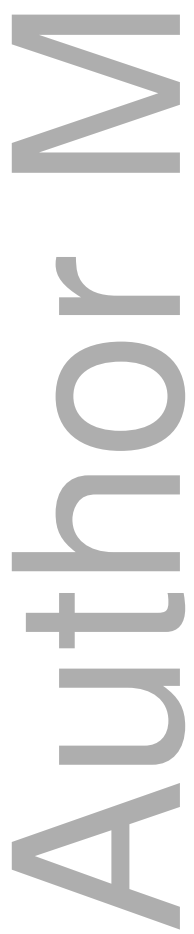

This article is protected by copyright. All rights reserved 
Table 1. Main trials evaluating the role of thromboprophylaxis in women with placenta-mediated pregnancy complications (in chronological order)

\begin{tabular}{|c|c|c|c|c|}
\hline 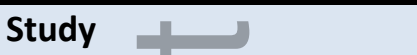 & Study population & Intervention & Endpoints & Conclusion \\
\hline $\begin{array}{l}\text { APLS in pregnancy } \\
(\mathbf{R C T})^{24} \\
\text { Farquharson et al. } 2002 \\
\text { Single centre } \\
1997-2000\end{array}$ & $\begin{array}{l}98 \text { women with recurrent } \\
\text { miscarriage ( } 3+ \\
\text { consecutive or } 2+>10 \\
\text { weeks) and APL antibodies, } \\
\text { recruited } \leq 12 \text { weeks }\end{array}$ & $\begin{array}{l}\text { Aspirin } 75 \text { mg vs aspirin plus } \\
\text { LMWH } 5000 \text { IU s.c. daily }\end{array}$ & Live-birth rate & $\begin{array}{l}\text { The addition of LMWH does not } \\
\text { significantly improve pregnancy } \\
\text { outcome ( } 72 \% \text { vs } 78 \% \text {; OR } 1.39,95 \% \\
\text { Cl } 0.55-3.47 \text { ) - fetal loss rate higher } \\
\text { in heparin group ( } 4 \text { vs } 8 \text { cases) }\end{array}$ \\
\hline $\begin{array}{l}\text { Gris et al. } 2004(\mathrm{RCT})^{21} \\
\text { Mediterranean Abnormal } \\
\text { Pregnancy Study } \\
\text { Program }\end{array}$ & $\begin{array}{l}160 \text { women with a single } \\
\text { unexplained pregnancy loss } \\
>10 \text { weeks and inherited } \\
\text { thrombophilia (Factor V } \\
\text { Leiden mutation, G20210A } \\
\text { mutation, protein S } \\
\text { deficiency) }\end{array}$ & $\begin{array}{l}\text { All patients received high- } \\
\text { dose folate } 5 \mathrm{mg} \text { daily }\end{array}$ & $\begin{array}{l}\text { Live-birth rate, } \\
\text { pregnancy loss rate, } \\
\text { haemorrhagic } \\
\text { complications, } \\
\text { birthweight }\end{array}$ & $\begin{array}{l}\text { Enoxaparin improves live-birth rates } \\
\text { ( } 29 \% \text { vs } 86 \% \text {; OR } 15.5 ; 95 \% \mathrm{Cl} 7-34 ; \\
P<0.0001 \text { ), and birthweight ( } 2742 \mathrm{~g} \\
\text { vs } 3043 \mathrm{~g} ; P<0.0005 \text { ) }\end{array}$ \\
\hline $\begin{array}{l}\text { LIVE-ENOX (RCT) } \\
\text { Brenner et al. } 2005 \\
12 \text { centres in Israel }\end{array}$ & $\begin{array}{l}180 \text { women with RPL ( } 3+ \\
\text { early losses, } 2+\text { mid- } \\
\text { trimester or fetal death in } \\
\text { utero) and thrombophilia }\end{array}$ & $\begin{array}{l}\text { Enoxaparin } 40 \mathrm{mg} \text { daily vs } \\
\text { enoxaparin } 40 \mathrm{mg} \text { twice daily }\end{array}$ & Live-birth rate & $\begin{array}{l}\text { No significant difference in } \\
\text { pregnancy outcome between groups } \\
(84.3 \% \text { vs } 78.3 ; P=0.484)\end{array}$ \\
\hline & & & & $\begin{array}{l}\text { Either treatment is effective and safe } \\
(2.7 \% \text { of women had allergic reaction }\end{array}$ \\
\hline
\end{tabular}

This article is protected by copyright. All rights reserved 


\begin{tabular}{|c|c|c|c|c|}
\hline HepASA trial $(\mathrm{RCT})^{23}$ & 88 patients with RPL and & Dalteparin 5000 IU s.c. daily & Live-birth rate & No difference in live-birth rates \\
\hline Laskin et al. 2009 & APL antibodies, inherited & until 35 weeks plus aspirin & & (77.8\% LMWH/aspirin group vs \\
\hline & thrombophilia, or & $81 \mathrm{mg}$ daily vs aspirin alone & & $79.1 \%$ ASA group; $P=0.71$ ) \\
\hline Canada & antinuclear antibodies & & & \\
\hline 2000-2004 & & & & $\begin{array}{l}\text { Trial was stopped after } 4 \text { years of } \\
\text { recruitment }\end{array}$ \\
\hline ALIFE (3-arm RCT) ${ }^{25}$ & 364 women with & Nadroparin 2850 IU s.c. daily & Primary: live-birth rate & Neither aspirin alone nor aspirin plus \\
\hline Kaandorp et al. 2010 & unexplained RPL (2+ & plus aspirin $80 \mathrm{mg}$ vs aspirin & Secondary: miscarriage & LMWH improved live-birth rates \\
\hline & miscarriages <20 weeks) & vs placebo & obstetrical & \\
\hline 5 sites, Netherlands & without APL antibodies, & & complications, maternal & \\
\hline $2004-200$ & recruited $<6$ weeks of & & and fetal adverse events & \\
\hline & gestation & & & \\
\hline & & & & \\
\hline SPIN (RCT) & 297 women with & Enoxaparin $40 \mathrm{mg}$ s.c. daily & Primary outcome: & No reduction in pregnancy loss rate \\
\hline Clark et al. 2010 & unexplained RPL (2+ & plus aspirin $75 \mathrm{mg}$ daily vs no & pregnancy loss rate & with pharmacological intervention \\
\hline & consecutive pregnancy & pharmacological treatment & & (22\% vs $20 \%$; OR $0.91,95 \% \mathrm{Cl} 0.52-$ \\
\hline 14 centres in UK, New & losses <24 weeks), & & & 1.59) \\
\hline Zealand & recruited $<7$ weeks & Both groups received & & \\
\hline & & intensive pregnancy & & \\
\hline 2004-2008 & & surveillance & & \\
\hline
\end{tabular}

This article is protected by copyright. All rights reserved 


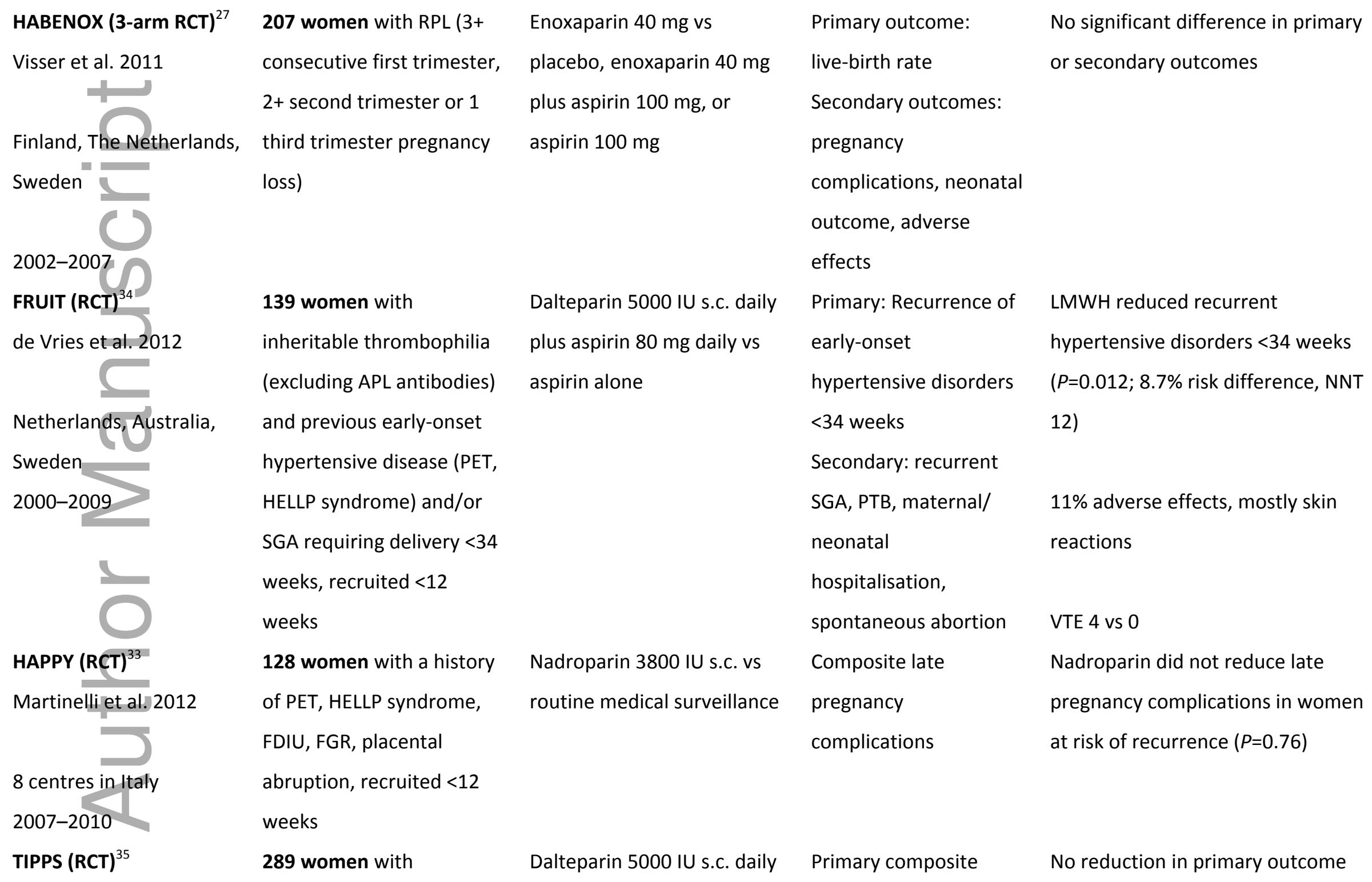

This article is protected by copyright. All rights reserved 
Rodger et al. 2014

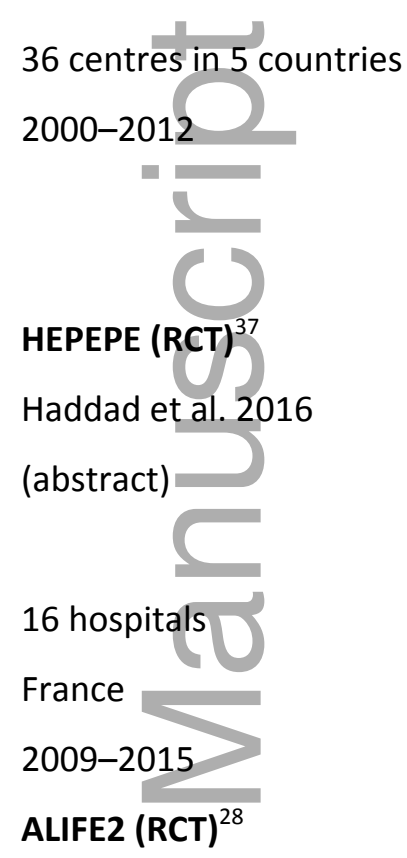

de Jong et al. 2015

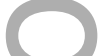

Currently recruiting
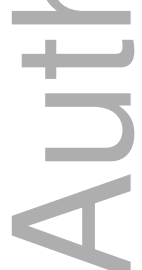

thrombophilia at increased

risk of VTE or with previous

placenta-mediated

pregnancy complications

(PET, FGR, abruption, RPL,

VTE)

257 women with history of

prior severe preeclampsia

<34 weeks (excluding

women with anticardiolipin

antibodies)

Women $<7$ weeks with

confirmed inherited

thrombophilia and a

history of $2+$ miscarriages

or intrauterine fetal death,

or both up to 20 weeks, then twice

daily until at least 37 weeks

vs no treatment

noxaparin 4000 IU (until

delivery) plus aspirin $100 \mathrm{mg}$

daily (until 35 weeks) vs

aspirin $100 \mathrm{mg}$ daily

Enoxaparin $40 \mathrm{mg}$ s.c. or
standard pregnancy
surveillance

outcome: severe or

early-onset PET, SGA

(birthweight <10th

centile), pregnancy loss,

VTE

\section{Primary composite}

morbidity: maternal and perinatal deaths, PET,

FGR (<10th centile),

abruption

\author{
Primary: live birth \\ Secondary: adverse \\ pregnancy outcome, \\ miscarriage, PET, HELLP \\ syndrome, FGR, \\ abruption, PTB, \\ congenital \\ malformations \\ Safety outcomes: \\ Commenced recruitment in January \\ 2013 with 23 women randomised; \\ aim to recruit 776 women
}

\section{(17.1\% vs $18.9 \%)$}

Minor bleeding more common in

LMWH group (19.6\% vs 9.2\%)

Enoxaparin added to low-dose aspirin does not significantly reduce placenta-mediated complications compared with aspirin alone

This article is protected by copyright. All rights reserved 
bleeding,

thrombocytopenia, skin

reactions

APL=antiphospholipid; APLS=antiphospholipid syndrome; FDIU=intrauterine fetal death; FGR=fetal growth restriction; LMWH=low-molecular-weight heparin; NNT=number needed to treat; $\mathrm{OR}=$ odds ratio; $\mathrm{PET}=$ severe pre-eclampsia; $\mathrm{PTB}=$ preterm birth; $\mathrm{RCT}=$ randomised controlled trial; $\mathrm{RPL}=$ recurrent pregnancy loss; s.c.=subcutaneously; SGA=small for gestational age; VTE=venous thromboembolism

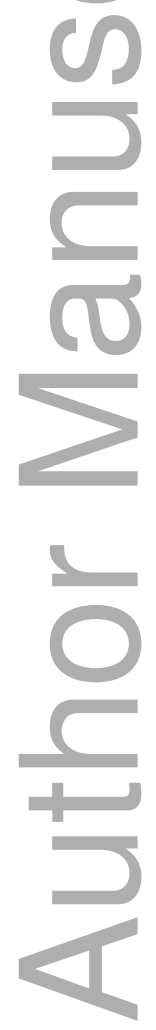

This article is protected by copyright. All rights reserved 


\section{University Library}

\section{- M M N E R VA A gateway to Melbourne's research publications}

Minerva Access is the Institutional Repository of The University of Melbourne

Author/s:

Unterscheider, J;Kane, SC;Cutts, B;Savoia, H;Said, JM

Title:

The role of thrombophilia testing in women with adverse pregnancy outcomes

Date:

2017-04-01

Citation:

Unterscheider, J., Kane, S. C., Cutts, B., Savoia, H. \& Said, J. M. (2017). The role of thrombophilia testing in women with adverse pregnancy outcomes. OBSTETRICIAN \& GYNAECOLOGIST, 19 (2), pp.163-172. https://doi.org/10.1111/tog.12366.

Persistent Link:

http://hdl.handle.net/11343/292732 